\title{
Analysis on the Construction of College English Teaching Evaluation System Based on Online Learning Platform
}

\author{
Xiaoming Chen \\ Haikou College of Economics, Haikou 571100, Hainan, China.
}

Abstract: With the rapid development of network information technology, it has been widely used in various fields. Of course, in the field of education is no exception. In college English teaching, the application of online learning platform can effectively improve the quality of college students' English learning and teaching effect. Starting from the importance of the construction of college English teaching evaluation system based on online learning platform, this paper puts forward the measures for the construction of college English teaching evaluation system for reference.

Keywords: Online Learning Platform; English Teaching; Evaluation System; Construction

\section{Introduction}

With the continuous development and progress of society, various online learning platforms have been widely used in college English teaching, updating the shortcomings of traditional classroom teaching and learning. It integrates the current information technology and traditional teaching methods to create a harmonious and open learning environment for students. In this environment, students can give full play to their imagination and mobilize their internal potential for better English learning. It's also more conducive to teachers' evaluation of students' English learning and adjustment their teaching methods and means according to students' feedback information, so as to improve the quality and efficiency of classroom teaching.

\section{The importance of the construction of college English teaching evaluation system based on online learning platform}

\subsection{Enriching classroom teaching resources}

College English is very difficult, especially oral English teaching. Some students have weak oral English foundation and are afraid of oral English class. The reason for this problem is not only students' own foundation, but also related to the lack of teaching resources available to English teachers in class. Under the background of the new era, with the influx of various online learning platforms, teachers can present the teaching content to students by means of pictures, videos, words and so on. Students can watch, download and learn independently, so as to improves the quality of classroom teaching. In addition, with the help of online learning platform, English teaching resources can be collected from all over the world, and teachers can also communicate with English education experts online ${ }^{[1]}$.

\subsection{Enriching the way of classroom teaching expression}

In the traditional college English classroom teaching, teaching expression methods of most of the teachers' teaching expression methods are very single. Some teachers directly translate the contents of the textbooks to the students, and simply 
describe the important and difficult contents. Some teachers organize the contents of the textbooks directly without processing and upgrading. In the process of classroom teaching, students can learn by themselves with the help of PPT, most of them think that they can learn by themselves from the textbook about the content that taught by teacher, and would rather self-study. With the construction of online learning platform, teachers can integrate the knowledge inside and outside the class, and present the knowledge content with the help of network channels, or students can learn by themselves from the online learning platform to obtain the learning content they want to know and study, in order to activate their enthusiasm and initiative in English learning ${ }^{[2]}$.

\subsection{Expanding the scope of teaching information exchange}

In the traditional classroom teaching, the communication between teachers and students is generally limited in the classroom, and the way of obtaining information between teachers and students is very simple. The application of online learning platform expands the way of communication between teachers and students. They can use E-mail and other ways for two-way information exchange. Students can freely express their own views and opinions in the platform, and teachers can understand the specific situation of students through the feedback information of students in the platform, for better teaching in the follow-up. Of course, the exchange and interaction with the help of online learning platform is not only limited between teachers and students, but also between teachers and students of our school and foreign teachers and students, which cannot be realized by traditional teaching methods ${ }^{[3]}$.

\section{Measures to construct college English teaching evaluation system based on online learning platform}

\subsection{Clarifying learning evaluation objectives}

\subsubsection{Objective of language knowledge evaluation}

Teachers should have a systematic understanding of the content of college English textbooks, collect all kinds of network learning platforms, and formulate various evaluation standards such as pronunciation in combination with the teaching contents of colleges and universities. For example, for the teaching and training of freshmen, online learning platform can be used to consolidate the basic language and vocabulary, in order to fill a vacancy leakage and make scientific evaluation; for the evaluation of sophomores, in addition to their basic English knowledge, the cross-cultural knowledge learning should be evacuated. Of course, for some students with good basic performance and strong language ability, the evaluation standard should be raised ${ }^{[4]}$.

\subsubsection{Objective of learning emotion evaluation}

The objective of this evaluation is to evaluate students' attitudes and emotions in learning English on the online learning platform, including the positive and negative emotions of students. In the construction of English teaching evaluation system, teachers should pay more attention to students' negative emotions, lead them to come out of the negative emotions through effective methods, so as to produce positive emotions, and bring them into the evaluation objectives ${ }^{[5]}$.

\subsection{Optimizing the learning evaluation process}

In the construction process of college English teaching evaluation system based on online learning platform, teachers should adjust the evaluation information effectively by means of information technology. With the help of computer network system or software, records and surveys are made, and the information is pushed to students on the platform. You can also obtain information by means of questionnaire recovery, or prediction of the relevant parameters in the platform system, in order to get accurate and reliable learning information in time by using the function of automatic collection of the system. In the evaluation of English teaching process, it is necessary to analyze the deep relationship between teachers and students, formulate a perfect evaluation process, and evaluate learning behavior and achievements of students. Then through the network system function, the students' English test results in different periods are collected, so as to have a comprehensive understanding of the progress or retrogression of students' academic achievements, and make evaluation on students according to relevant standards. In addition, we can learn about the students' learning situation and the application of the online learning platform by means of discussion and spot check, and provide them with guidance. In this way, the scientificity, perfection and effectiveness of the English teaching evaluation process can be reflected. 


\subsection{Adjusting the way of learning evaluation}

\subsubsection{Teacher evaluation}

Teachers play the role of organizer, guide and participant in the online learning platform. They can complete and understand the completion status of students' English homework, observe students' learning behavior and classroom performance, and evaluate students' test performance according to actual needs. In specific teaching, teachers should build a complete file information database with the help of online learning platform, input students' basic information, English scores, classroom performance and other data into the database, and provide targeted guidance for students' problems in learning, so that students can overcome the difficulties of English learning in time, and can make more effective use of online learning platform for English learning. In the process of summative evaluation, teachers can obtain students' test results through network test and other ways, and make a comprehensive score by integrating students' learning performance and other data in the database ${ }^{[6]}$.

\subsubsection{Student evaluation}

In the construction of college English teaching evaluation system, student evaluation is an important part, including selfevaluation and mutual evaluation. Through evaluation, students can clearly understand their own advantages and disadvantages, and make self-regulation and reflection in the evaluation, so as to develop good learning habits. In the specific evaluation, the students' basic achievement level and needs should be combined to formulate English learning objectives. Meanwhile, English online platform learning groups can be built, mutual evaluation in the group, each group mutual evaluation, or upload the student self-assessment form on the online learning platform, mutual evaluation with anonymous method.

\subsubsection{System evaluation}

For constructing the English teaching evaluation system, teachers can integrate the information and data of the students from the online learning platform and database. After completing the learning tasks of each class or stage, students can trigger the system evaluation by means of online teaching application. The evaluation system will obtain relevant information according to the issued instructions, and carry out personalized evaluation on students in combination with the pre input evaluation principle.

\section{Conclusion}

In short, online learning platform has become a very important tool for college English teaching and learning. In the construction of college English teaching evaluation system based on online learning platform, teachers need to clarify learning evaluation objectives, optimize learning evaluation process, and adjust learning evaluation methods to guide students to participate in the evaluation process, so as to ensure the scientific and effective construction of college English teaching evaluation system.

\section{References}

1. Wei J. Construction of formative evaluation index system of college English based on e-learning platform. Guangxi Education (Higher Education) 2019; 2(8): 220-221.

2. Wei J. Formative assessment of college English teaching based on e-learning platform. Higher Education Forum 2019; 3(12): 123-125.

3. Wang H, Zhang J. An effective evaluation model of college English online autonomous learning under constructivism. Science and Technology 2019; (26).

4. Zhang Y. Research on the multiple evaluation system of college English learning under the information technology environment. Education Modernization 2020; 5(9): 132-133.

5. Zheng Y. Evaluation based model of college English in autonomous learning environment. Education Informatization in China 2019; 6(15): 41-45.

6. Cheng Q. A study on the feedback strategies of formative assessment in Web-based autonomous learning of college English. Science and Technology Perspective 2019; 10(12): 71-72. 